\title{
EFEITO DO MATERIAL GENÉTICO E DO SÍTIO NA QUALIDADE DO CARVÃO VEGETAL DE MADEIRA DE CURTA ROTAÇÃO
}

\author{
Angélica de Cássia Oliveira Carneiro ${ }^{1}$, Benedito Rocha Vital ${ }^{1}$, Pedro Gustavo Ulisses Frederico ${ }^{2}$, \\ Lucas de Freitas Fialho ${ }^{2 *}$, Clarissa Gusmão Figueiró ${ }^{2}$, Carlos Miguel Simões da Silva ${ }^{2}$ \\ ${ }^{1}$ Universidade Federal de Viçosa, Departamento de Engenharia Florestal, Viçosa, Minas Gerais, Brasil - cassiacarneiro1 @ gmail.com; \\ bvital@ufv.br \\ $2^{2 *}$ Universidade Federal de Viçosa, Programa de Pós-Graduação em Ciência Florestal, Viçosa, Minas Gerais, Brasil - \\ pedrogufrederico@hotmail.com; 1.freitasfialho@gmail.com; clarissagfigueiro@gmail.com; karmiguel@yahoo.com.br \\ Recebido para publicação: 03/03/2016 - Aceito para publicação: 31/08/2016
}

\begin{abstract}
Resumo
O objetivo do presente estudo foi avaliar o efeito do material genético e do local de plantio no carvão vegetal produzido com madeira de eucalipto proveniente de sistemas de curta rotação. Foram avaliados cinco clones de Eucalyptus spp. provenientes de três munícipios do estado de Minas Gerais. Foram carbonizadas amostras de cavacos em forno elétrico do tipo mufla, com taxa de aquecimento de $1,67^{\circ} \mathrm{C} / \mathrm{min}$ e avaliados os seguintes parâmetros do carvão resultante: rendimento em carvão vegetal, composição química imediata (carbono fixo, materiais voláteis e cinzas), densidade aparente e poder calorífico superior. Observou que ambas as variáveis, ou seja, material genético e localidade de plantio possuem efeito significativo no rendimento em carvão vegetal, na composição química imediata e no poder calorífico. Já a densidade do carvão não foi afetada por nenhuma das duas variáveis. $\mathrm{O}$ rendimento e a densidade ficaram abaixo dos valores citados pela literatura para carvão produzido, nas mesmas condições laboratoriais, com madeira proveniente de sistemas convencionais com maior idade de corte. De modo geral, pode-se observar a importância de se avaliar o potencial para a produção de carvão individualmente. Além disso, evidenciou-se que os clones de Eucalyptus spp. provenientes de sistemas de curta rotação são menos indicadas para a produção de carvão do que as de sistemas convencionais.

Palavras-chave: Local de plantio; eucalipto; rendimento em carvão.
\end{abstract}

\begin{abstract}
Effect of genetic materials and the site in charcoal quality of short rotation wood. The aim of this study was to evaluate the effect of genetic material and the planting location on charcoal produced from eucalyptus wood from short rotation systems. It was evaluated five clones of Eucalyptus sp. from three municipalities of the state of Minas Gerais. Wood chip samples were charred in electric oven muffle, with heating rate of $1.67^{\circ} \mathrm{C} / \mathrm{min}$ and evaluated the following parameters of the resulting carbon: Yield charcoal, Proximate composition (fixed carbon, volatiles matter and ash), Density apparent and Higher heating value. Was noted that both variables genetic material and planting location - had a significant effect on yield charcoal, in proximate composition and higher heating value. Already the coal density was not affected by any of the two variables. The yield and density were below the values reported in the literature for coal produced under the same laboratory conditions, with wood from conventional systems with older cut. In general, it can be observed the importance of assessing the potential for the production of coal individually. Furthermore, it was shown that clones of Eucalyptus spp. from short rotation systems are less suitable for charcoal production than conventional systems.

Keywords: Planting location; Eucalyptus; yield charcoal.
\end{abstract}

\section{INTRODUÇÃO}

O carvão vegetal representa uma excelente matéria-prima para a siderurgia brasileira, devido ao seu comportamento como combustível e redutor, elevado grau de pureza, baixo custo de produção e por ser um produto renovável e ambientalmente correto quando oriundo de florestas plantadas. Um problema relacionado à utilização do carvão vegetal é sua alta variabilidade em qualidade, uma vez que esse produto sofre grande influência da madeira que the deu origem e do sistema de produção. Essa variabilidade ocasiona grande desperdício do material, pois dificulta a operação dos alto-fornos siderúrgicos (OLIVEIRA et al., 2010).

A qualidade do carvão vegetal utilizado na siderurgia influencia na qualidade do produto final. A qualidade e a quantidade do carvão vegetal produzido dependem basicamente de características físico-químicas da madeira e do processo de produção. Por tanto é necessário conhecer essas características, o processo de produção e a correlação entre elas (PEREIRA et al., 2013). 
Para a produção de carvão vegetal, por exemplo, preferem-se madeiras com maiores densidades e maiores teores de lignina, enquanto para a produção de celulose e papel estas características são indesejáveis (GOMIDE et al., 2005; CASTRO et al., 2013).

Atualmente, a demanda crescente por madeira induz o setor de florestas plantadas a investir em pesquisa para cada vez mais aumentar a produtividade dos plantios e reduzir a idade de corte dos mesmos. Nesse contexto, as florestas de curta rotação surgem com alternativas, especialmente para o setor energético, para obtenção de madeira em intervalos de tempo reduzido e com custos inferiores de produção (ELOY et al., 2015). Todavia, a madeira de curta rotação apresenta qualidade distinta das produzidas em sistemas florestais convencionais devido à variabilidade que ocorre em função da idade do indivíduo (OLIVEIRA et al., 2010).

Com isso, o objetivo do presente estudo foi avaliar o rendimento e as propriedades do carvão vegetal produzido com madeira de curta rotação obtida de diferentes materiais genéticos de Eucalyptus spp. provenientes de diferentes locais de plantio.

\section{MATERIAL E MÉTODOS}

Foram avaliadas amostras de carvão vegetal produzidas com madeiras de cinco materiais genéticos, sendo o clone I da espécie Eucalyptus grandis e os clones II, III, IV e V de híbridos das espécies Eucalyptus grandis x Eucalyptus urophylla provenientes dos municípios de Santa Bárbara, Guanhães e Ipaba, localizados no estado de Minas Gerais. Selecionaram-se árvores com diâmetro médio ( \pm desvio-padrão), em uma parcela de 10 x 10 plantas. Foram colhidas cinco árvores-amostra, por clone e local, totalizando 75 amostras. Os clones foram coletados em plantios comerciais com espaçamento de 3,0 x 3,3 m, aos 3 anos de idade, com densidade média entre 420 e $470 \mathrm{Kg} / \mathrm{m}^{3}$.

Os materiais genéticos foram cultivados em três localidades do estado de Minas Gerais, sendo: Santa Bárbara (Mesorregião Metropolitana de Belo Horizonte): Maior índice de pluviosidade anual (1400-1600 mm); solo de profundidade variada, textura argilo-arenosa e baixa fertilidade natural. Guanhães (Mesorregião do Vale do Rio Doce): Menor índice de pluviosidade anual (1100-1200 mm); solo profundo, textura argilosa e de baixa fertilidade natural. Ipaba (Mesorregião do Vale do Rio Doce): Menor índice de pluviosidade anual (1000$1200 \mathrm{~mm}$ ); solo profundo, textura argilo-arenosa e de alta fertilidade natural.

Foram escolhidas cinco árvores de cada material de acordo com o diâmetro médio do respectivo povoamento. De cada árvore foram retirados toretes a 0,25, 50, 75 e 100\% da altura comercial considerada até o diâmetro mínimo de sete centímetros. Os toretes foram reduzidos a cavacos em picador industrial, selecionados em peneira de malha $25 \mathrm{~mm}$ e homogeneizado em uma amostra composta para cada árvore.

As amostras selecionadas foram secas em estufa a $103 \pm 2{ }^{\circ} \mathrm{C}$ até atingirem umidade de $0 \%$. A carbonização foi realizada em um forno elétrico do tipo mufla, utilizando-se $200 \mathrm{~g}$ de cavacos absolutamente secos que foram inseridos em um container metálico com volume interno de aproximadamente $0,003 \mathrm{~m}^{3} \mathrm{e} \mathrm{com}$ adaptação para a saída dos gases. A temperatura inicial de carbonização foi de $100{ }^{\circ} \mathrm{C}$, sendo elevada a uma taxa de aquecimento de $1,67^{\circ} \mathrm{C} / \mathrm{min}$ até a temperatura de $450{ }^{\circ} \mathrm{C}$, onde permaneceu por mais 30 minutos até ser retirado do equipamento.

O rendimento gravimétrico em carvão vegetal foi calculado dividindo-se a massa seca final pela massa seca inicial de cada carbonização. A composição química imediata do carvão (materiais voláteis, carbono fixo e cinzas) foi determinada de acordo com a norma ABNT NBR 8112 (1986). A densidade relativa aparente foi determinada pelo método de imersão em mercúrio citado por Vital (1984) e pela norma ABNT NBR 11941 (1985). O poder calorífico superior foi determinado de acordo com a norma ABNT NBR 8633 (1984).

Os dados foram analisados segundo um fatorial $5 \times 3$ (cinco materiais genéticos e três localidades de plantio), com cinco repetições (árvores) cada, totalizando 75 unidades amostrais (carbonizações). Os resultados foram submetidos à análise de variância (ANOVA) e, quando estabelecidas diferenças significativas, os tratamentos foram comparados entre si por meio do teste de Tukey a 5\% de significância. Para determinar as correlações entre as propriedades, foi empregado o coeficiente de correlação de Pearson, que mede o grau de associação linear entre duas variáveis quantitativas. As análises estatísticas foram realizadas com o auxílio dos programas SAEG 9.1 (2007) e STATISTICA 8.0 (2007).

\section{RESULTADOS}

Os valores médios de rendimento gravimétrico em carvão vegetal em função dos materiais genéticos e das localidades de plantio avaliadas estão ilustrados na figura 1. Observa-se que, de modo geral, houve efeito significativo das duas variáveis nos valores de rendimento encontrados. 


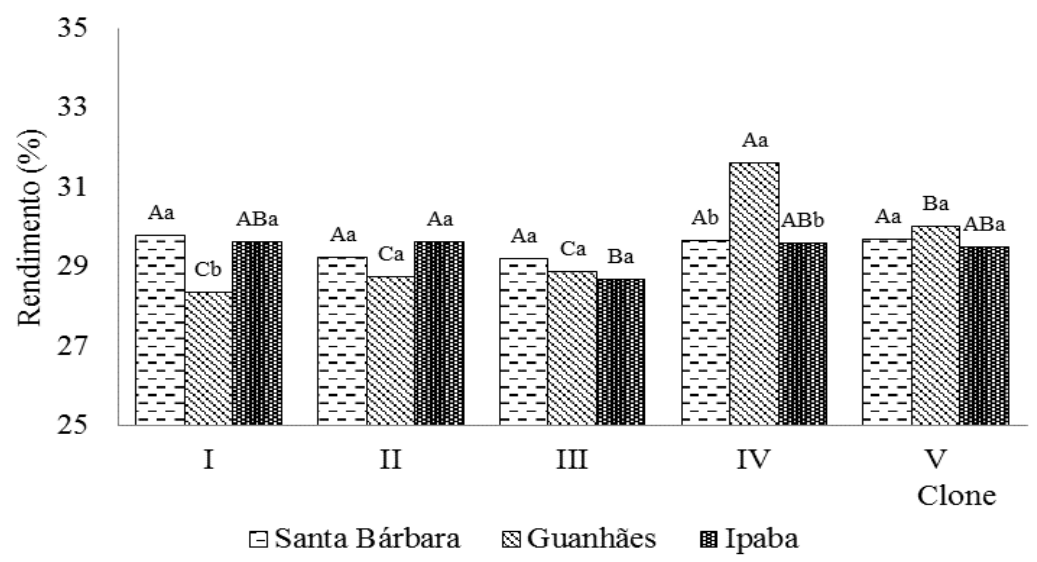

Médias seguidas de mesma letra maiúscula entre clones e minúscula entre regiões de plantios não diferem entre si pelo teste Tukey a $5 \%$ de significância.

Figura 1. Rendimento em carvão vegetal de Eucalyptus spp. em função do material genético e do local de plantio.

Figure 1. Yield eucalyptus charcoal as a function of the genetic material and the planting site.

Na figura 2 estão apresentados os teores médios da composição química imediata, ou seja, os teores de Materiais Voláteis (MV); Cinzas (CZ) e Carbono Fixo (CF), do carvão vegetal em função dos materiais genéticos e das três localidades de plantio avaliadas. Observa-se que, de modo geral, houve efeito significativo das duas variáveis nos valores encontrados.
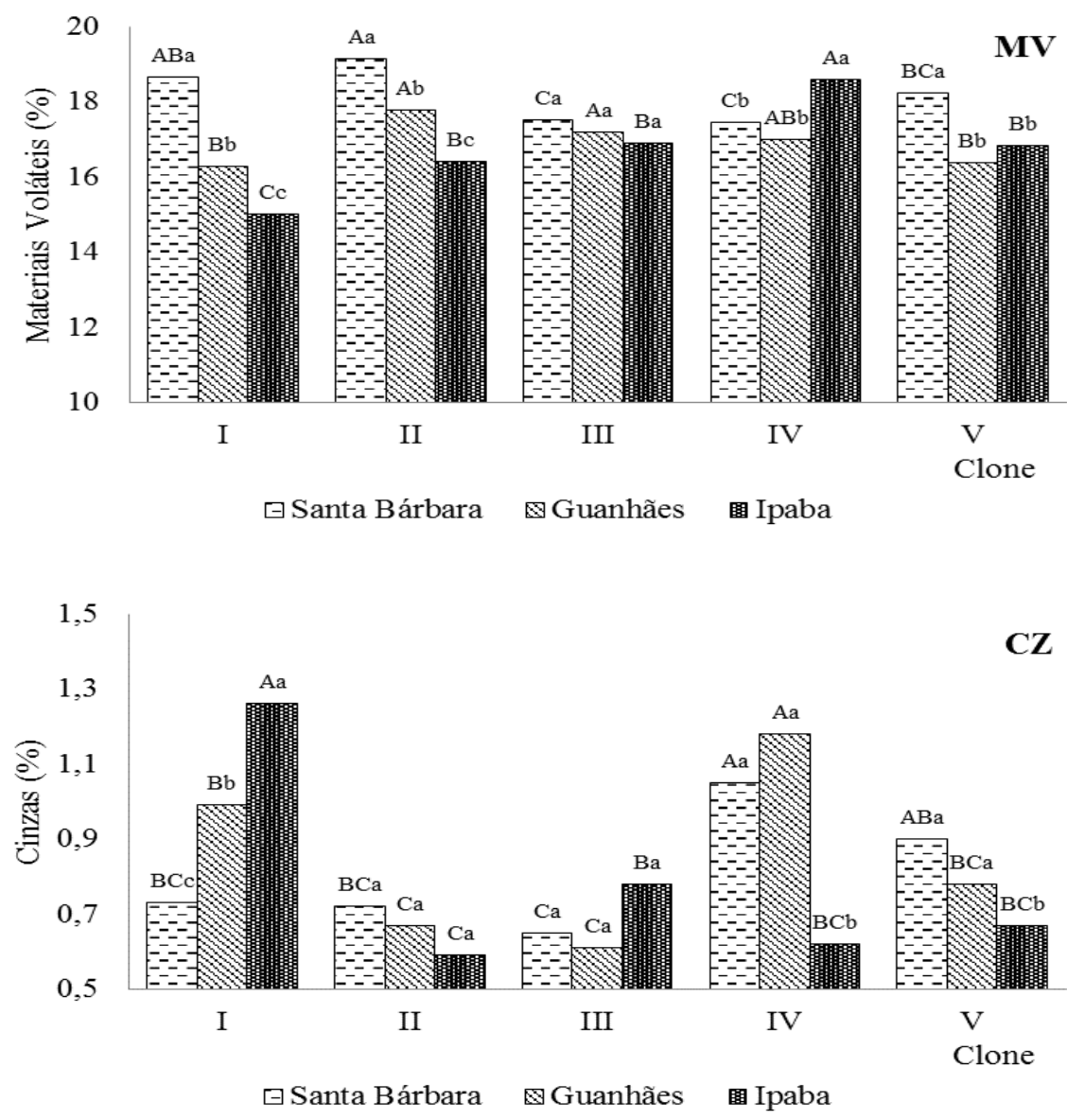

FLOREST A, Curitiba, PR, v. 46, n. 4, p. 473 - 480, out. / dez. 2016.

Carneiro, A. de C. O. et al.

ISSN eletrônico 1982-4688

DOI: $10.5380 /$ rf.v46i3.45704 


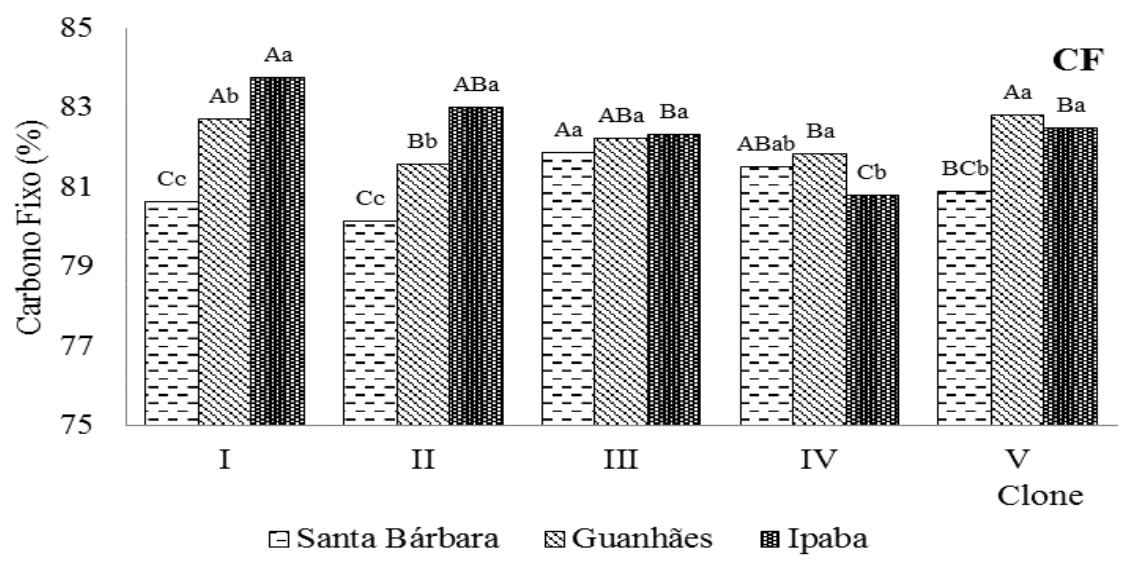

Médias seguidas de mesma letra maiúscula entre clones e minúscula entre regiões de plantios não diferem entre si pelo teste Tukey a 5\% de significância.

Figura 2. Materiais Voláteis (MV), Cinzas (CZ) e Carbono Fixo (CF) do carvão vegetal de Eucalyptus spp. em função do clone e do local de plantio.

Figure 2. Volatile Matter (MV), Ash (CZ) and Fixed Carbon (CF) of eucalyptus charcoal depending on the clone and the planting site.

$\mathrm{Na}$ figura 3 estão os valores médios de densidade relativa aparente do carvão vegetal em função dos materiais genéticos e das três localidades de plantio avaliadas. Não foram encontradas diferenças significativas, por meio da análise de variância a 5\% de significância, para nenhuma das duas variáveis avaliadas.

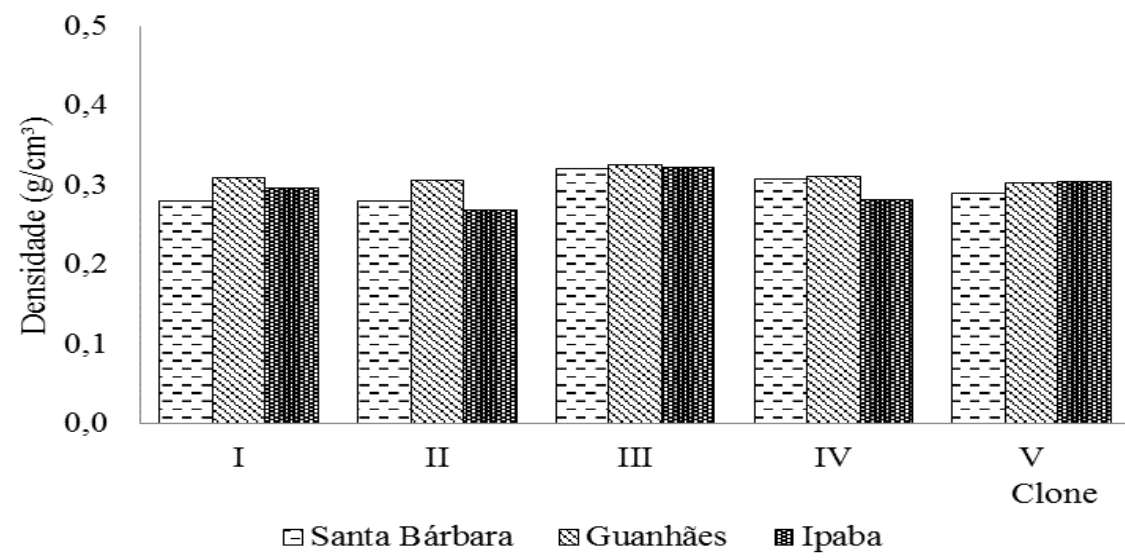

Figura 3. Densidade aparente do carvão vegetal de Eucalyptus spp. em função do clone e do local de plantio. Figure 3. Bulk density of eucalyptus charcoal depending on the clone and the planting site.

Os valores médios de Poder Calorífico Superior (PCS) do carvão vegetal em função dos materiais genéticos e das três localidades de plantio avaliadas são apresentados na figura 4. Observa-se que, de modo geral, houve efeito significativo das duas variáveis nos valores encontrados. 


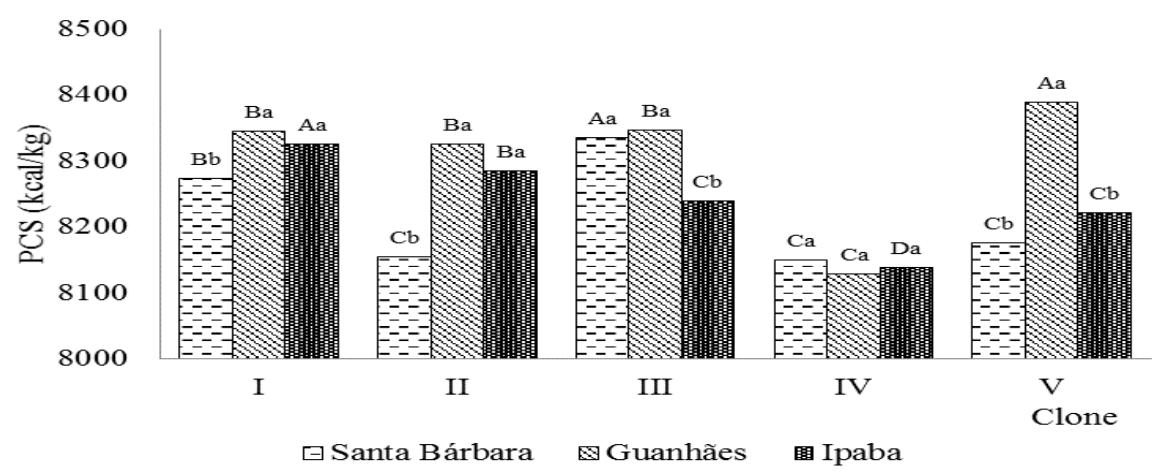

Médias seguidas de mesma letra maiúscula entre clones e minúscula entre regiões de plantios não diferem entre si pelo teste Tukey a 5\% de significância.

Figura 4. Poder Calorífico Superior (PCS) do carvão vegetal de Eucalyptus spp. em função do clone e do local de plantio.

Figure 4. Higher Heating Value (HHV) of eucalyptus charcoal depending on the clone and the planting site.

Na tabela 1 são apresentadas as correlações existentes entre o rendimento e as propriedades avaliadas do carvão produzido. Observam-se cinco correções significativas das 25 combinações possíveis.

Tabela 1. Matriz de correlações entre as propriedades do carvão vegetal de Eucalyptus spp.

Table 1. Correlation matrix among the properties of eucalyptus charcoal.

\begin{tabular}{lllllll}
\hline & RCV & MV & CZ & CF & DA & PCS \\
\hline RCV & 1 & $-0,017$ & 0,409 & $-0,068$ & $-0,210$ & $-0,440^{*}$ \\
MV & --- & 1 & $-0,464^{*}$ & $-0,982^{*}$ & $-0,304$ & $-0,522^{*}$ \\
CZ & --- & --- & 1 & 0,290 & 0,146 & $-0,178$ \\
CF & --- & --- & --- & 1 & 0,296 & $0,601^{*}$ \\
DA & --- & --- & --- & --- & 1 & 0,292 \\
PCS & --- & --- & --- & --- & -- & 1 \\
\hline
\end{tabular}

Correlações significativas a 5\%* de probabilidade pelo teste $\mathrm{T}$.

Legenda: Rendimento em Carvão Vegetal (RCV); Materiais Voláteis (MV); Cinzas (CZ); Carbono Fixo (CF); Densidade Aparente (DA); Poder Calorífico Superior (PCS).

\section{DISCUSSÃO}

Para o rendimento gravimétrico em carvão vegetal (Figura 1), foi observada uma maior amplitude nas diferenças significativas entre os materiais genéticos cultivados na localidade de Guanhães. Na localidade de Ipaba, apenas para o clone III o rendimento gravimétrico foi estatisticamente inferior aos demais. Já em Santa Bárbara, não houve diferenças significativas entre os clones.

Os maiores rendimentos em carvão foram observados para o clone I em Santa Bárbara e Ipaba; e para a localidade de Guanhães o maior rendimento gravimétrico foi observado no clone IV. Para os demais clones não foi observado diferenças significativas quando cultivados em localidades diferentes.

O rendimento gravimétrico em carvão depende tanto das variáveis inerentes à própria madeira quanto das condições do processo de carbonização. Como as amostras foram utilizadas nas mesmas dimensões, umidades e foram carbonizadas nas mesmas condições e taxas de aquecimento, as diferenças encontradas no rendimento estão diretamente relacionadas à composição química da madeira em função do material genético e da localidade de plantio.

As propriedades da madeira, como a composição química, são variáveis em função de fatores genéticos, condições edafoclimáticas, tratamentos silviculturais e idade (GOULART et al., 2003; OLIVEIRA et al., 2013). As variações nos teores de holoceluloses (polissacarídeo) e ligninas influenciam diretamente no rendimento gravimétrico em carvão vegetal. As holoceluloses são a fração que menos contribui para o rendimento, enquanto a lignina é o constituinte que mais contribui por ter alta estabilidade térmica e altos teores de carbono (HAYKIRI-ACMA et al., 2010; PEREIRA et al, 2013). Os materiais genéticos de maior rendimento, portanto, possivelmente apresentaram maiores teores de ligninas e menores de holoceluloses na sua constituição (CASTRO et al, 2013).

Seguindo essa pressuposição, o maior rendimento geral em carvão do clone IV pode ser função de um possível maior teor relativo de lignina em relação ao teor de holoceluloses. Já o clone III, possivelmente, 
apresenta os menores teores devido ao menor rendimento, evidenciando que as propriedades químicas são variáveis até mesmo dentro de clones da mesma espécie. Assim, a destinação correta do uso da madeira para a produção de carvão depende, dentre outras variáveis, da sua constituição química com maiores teores de lignina.

As condições edafoclimáticas apresentadas pela localidade de Ipaba, como baixo índice de pluviosidade e baixa fertilidade natural do solo, são teoricamente as menos propícias para o desenvolvimento da planta. Com isso, evidencia o maior efeito genético do material, como o clone IV que se apresentou mais adaptado as condições citadas. Já em Santa Bárbara, pelo índice de pluviosidade favorável, e Ipaba, pela fertilidade favorável do solo, a variação entre clones não ficou tão distinta.

Os valores de rendimento em carvão vegetal encontrados nos presentes estudos estão abaixo dos normalmente encontrados para madeira de Eucalyptus quando carbonizada em condições laboratoriais semelhantes, conforme citado por Neves et al. (2011), Oliveira et al. (2012) e Pereira et al. (2013). O menor rendimento se deve ao fato da madeira utilizada ser provenientes de árvores mais jovens. O processo de lignificação tem correlação com o desenvolvimento do tecido madeireiro, portanto árvores mais velhas tendem a apresentar maiores teores de lignina. Essa diferença resulta nos maiores rendimentos em carvão produzidos com madeira a partir de árvores mais velhas com relação de árvores mais jovens (CASTRO et al., 2013).

Avaliando o carvão produzido com os materiais provenientes de Santa Bárbara (Figura 2), observa-se os maiores teores de carbono fixo e os menores de materiais voláteis e cinzas para o clone III, mesma tendência observada para o clone V em Guanhães. Em Ipaba, por sua vez, os maiores teores de carbono fixo e os menores valores de materiais voláteis foram verificados para o clone I, mas com os maiores valores de cinzas. Os menores teores de cinzas nessa localidade foram observados no clone II, com baixos teores de materiais voláteis e consequentemente altos de carbono fixo.

O carvão com maior teor de carbono fixo e menor de materiais voláteis foi verificado para o clone I quando cultivado em Ipaba e os menores teores de cinzas quando cultivado em Santa Bárbara. Essa tendência foi observada para o clone IV, respectivamente, para as localidades de Guanhães e Ipaba. O carvão com maiores teores de carbono fixo e menores de materiais voláteis e cinzas foram observados nos clones II e V quando cultivados em Ipaba. Não ocorreu diferença significativa na composição química em função das localidades para o clone III.

A composição química imediata define a qualidade do carvão vegetal, já que os maiores teores de carbono fixo refletem em maior rendimento de utilização e os menores teores de cinzas refletem em menores desgastes e gastos com limpezas dos equipamentos utilizados (OLIVEIRA et al., 2012). Segundo Pereira et al. (2013), a composição química do carvão apresenta correlação direta com a composição química da matériaprima que lhe deu origem, na qual maiores teores de carbono e menores teores de cinzas tendem a produzir com maiores teores de carbono e menores de cinzas.

Todavia, a composição química do carvão apresenta influência no processo de carbonização, já que o processo é caracterizado como sendo um tratamento térmico que elimina seletivamente os materiais voláteis e, consequentemente, concentra carbono fixo no material sólido final (OLIVEIRA et al., 2010). A degradação térmica para a eliminação de voláteis está relacionada com a perda de massa que é inversamente proporcional ao rendimento gravimétrico. Assim, espera-se que menores rendimentos gravimétricos, ou seja, maiores perdas de massa estejam associadas à redução nos teores de materiais voláteis e à consequente concentração dos teores de carbono fixo no carvão.

A maior densidade, assim como o maior teor de carbono fixo, influencia positivamente no rendimento do uso final do carvão vegetal. Por exemplo, carvão de maior densidade eleva a capacidade de carga do alto-forno para produção do ferro-gusa nas indústrias siderúrgicas, principal setor consumidor desse insumo no Brasil.

A densidade relativa aparente encontrada no presente estudo (Figura 3) está abaixo dos valores encontrados para o carvão produzido com madeira de Eucalyptus, conforme encontrados e discutidos por Oliveira et al. (2012). Os autores, estudando diferentes clones de E. grandis $x$ E. urophylla, encontraram valores de densidade do carvão variando de 0,390 a $0,438 \mathrm{~g} / \mathrm{cm}^{3}$, valores inferiores aos obtidos neste trabalho. As diferenças entre a densidade aparente dos carvões podem ser explicadas pela maior densidade básica da madeira dos clones estudados pelos autores, uma vez que a densidade do carvão está diretamente correlacionada com densidade da madeira de origem.

Árvores mais jovens tendem a ter uma proporção mais significativa de lenho juvenil, fração da madeira produzida sob maior influência direta do meristema apical e menor densidade do que o lenho maduro (DELUCIS et al., 2014). Assim, a baixa densidade das madeiras utilizada apresentava densidade menor por ter apenas três anos de idade, diferente dos demais trabalhos que utilizaram madeira de árvores mais velhas normalmente acima de seis anos.

O carvão produzido com a madeira do clone III apresentou o maior poder calorífico dentre os materiais cultivados em Santa Bárbara, enquanto o carvão do clone V foi o maior dentre os cultivados em Guanhães e o clone I dentre os cultivados em Ipaba (Figura 4). 
Os carvões produzidos com madeira dos clones I e II apresentaram os maiores valores de poder calorífico quando estes foram cultivados em Guanhães e Ipaba. O carvão do clone III apresentou maior valor quando cultivado em Santa Bárbara e Guanhães. O clone IV não apresentou diferenças significativas entre localidades. Já clone V apresentou o maior valor de poder calorífico quando cultivado em Guanhães.

O poder calorífico representa a quantidade potencial de energia, por unidade de massa, que o combustível é capaz de liberar durante a combustão. O poder calorífico do carvão está diretamente correlacionado ao teor de carbono fixo e inversamente correlacionado aos teores de materiais voláteis e de cinzas (DU et al., 2014). Por contribuir positivamente para a geração de energia e devido aos seus maiores valores percentuais no carvão, o carbono é o elemento que apresenta maior contribuição para o poder calorífico. As cinzas é a fração inerte dos inorgânicos que não é degradada durante a combustão, não contribuindo, portanto, para a geração de energia.

De acordo com a tabela 1, o teor de materiais voláteis apresenta correlação negativa com os teores de carbono fixo e de cinzas porque durante a carbonização existe a degradação térmica com a eliminação dos voláteis que, consequentemente, resulta na concentração dos teores dos demais compostos no carvão. O poder calorífico tem correlação positiva com o teor de carbono fixo e negativa com rendimento em carvão e com os materiais voláteis devido à perda de massa ocorrida durante a carbonização no intuito de concentrar carbono e energia na fração sólida final.

As propriedades do carvão vegetal são parâmetros fundamentais para a avaliação e seleção de materiais genéticos superiores para produção de carvão vegetal. Estudar as características do carvão vegetal propicia a condução da escolha da madeira com propriedades desejáveis para sua conversão energética (OLIVEIRA et al; 2010).

\section{CONCLUSÕES}

- De modo geral, o rendimento e a qualidade do carvão vegetal produzido com madeira de eucalipto tem influência direta do material genético utilizado e das condições edafoclimáticas do local de plantio.

- O poder calorífico do carvão é influenciado pelo rendimento gravimétrico e pela composição química do mesmo.

- Madeira de eucalipto proveniente de plantios de curta rotação tende a apresentar menor rendimento e menor densidade no carvão vegetal com relação à madeira proveniente de plantios mais velhos.

\section{AGRADECIMENTOS}

Vegetal.

Ao CPNq, a CAPES, a FAPEMIG, Embrapa Florestas, SIF e ao G6 - Grupo Temático em Carvão

\section{REFERÊNCIAS}

ASSIS, M. R.; PROTÁSIO, T. P.; ASSIS, C. O.; TRUGILHO, P. F.; SANTANA, W. M. S. Qualidade e rendimentos do carvão vegetal de um clone híbrido de Eucalyptus grandis x Eucalyptus urophylla. Pesquisa Florestal Brasileira, Colombo, v. 32, n. 71, p. 291-302, 2012.

ASSOCIAÇÃO BRASILEIRA DE NORMAS TÉCNICAS (ABNT). NBR 8633: Carvão vegetal - Determinação do poder calorífico. Rio de Janeiro: 1984. 13 p.

NBR 9165: Carvão vegetal - Determinação da densidade relativa aparente, relativa verdadeira e porosidade. Rio de Janeiro: 1985.8 p.

NBR 8112: Carvão vegetal - Análise imediata. Rio de Janeiro: 1983. 5 p.

CASTRO, A. F. N. M.; CASTRO, R. V. O.; CARNEIRO, A. C. O.; LIMA, J. E.; SANTOS, R. C.; PEREIRA, B. L. C.; ALVES, I. C. N. Análise multivariada para seleção de clones de eucalipto destinados à produção de carvão vegetal. Pesquisa Agropecuária Brasileira, Brasília, v. 48, n. 6, p. 627-635, 2013.

DELUCIS, R. A.; GATTO, D. A.; STANGERLIN, D. M.; BELTRAME, R. Métodos de delimitação dos lenhos juvenil e adulto de três folhosas e propriedades biométricas de suas fibras. Revista Árvore, Viçosa, v. 38, n. 5, p. 943-950, 2014.

DU, S.; CHEN, W.; LUCAS, J. A. Pretreatment of biomass by torrefaction and carbonization for coal blend used in pulverized coal injection. Bioresource Technology, v. 161, p. 333-339, 2014. 
ELOY, E.; CARON, B. O.; SIlVA, D. A.; SOUZA, V. Q.; TREVISAN, R.; BEHLING, A.; ELli, E. F. Produtividade energética de espécies florestais em plantios de curta rotação. Ciência Rural, Santa Maria, v. 45, n. 8, p. 1424-1431, 2015.

EVANGELISTA W. V.; SILVA, J. C.; DELlA LUCIA, R. M.; LOBO, L. M.; SOUZA, M. O. A. Propriedades físico-mecânicas da madeira de Eucalyptus urophylla S. T. Blake no sentido radial e longitudinal. Ciência da Madeira, Pelotas, v. 1, n. 2, p. 1-19, 2010.

GOMIDE, J. L.; COLODETTE, J. L.; OLIVEIRA, R. C.; SILVA, C. M. Caracterização tecnológica, para produção de celulose, da nova geração de clones de Eucalyptus do Brasil. Revista Árvore, Viçosa, v. 29, n. 1, p. 129-137, 2005.

HAYKIRI-ACMA, H.; YAMAN, S.; KUCUKBAYRAK, S. Comparison of the thermal reactivities of isolated lignin and holocelluloses during pyrolysis. Fuel Processing Technology, v. 91, p. 759-764, 2010.

NEVES, T. A.; PROTÁSiO, T. P.; COUTO, A. M.; TRUGILHO, P. F.; SilvA, V. O.; VIEIRA, C. M. M. Avaliação de clones de Eucalyptus em diferentes locais visando à produção de carvão vegetal. Pesquisa Florestal Brasileira, Colombo, v. 31, n. 68, p. 319-330, 2011.

OLIVEIRA, A. C.; ROCHA, M. F. V.; PEREIRA, B. L. C.; CARNEIRO, A. C. O.; CARVALHO, A. M. M. L.; VITAL, B. R. Avaliação de diferentes níveis de desbaste nas propriedades da madeira e do carvão vegetal de Eucalyptus grandis x Eucalyptus urophylla. FLORESTA, Curitiba, v. 42, n. 1, p. 59-68, 2012.

OLIVEIRA, A. C.; CARNEIRO, A. C. O.; VITAL, B. R.; ALMEIDA, W.; PEREIRA, B. L. C.; CARDOSO, M. T. Parâmetros de qualidade da madeira e do carvão vegetal de Eucalyptus pellita F. Muell. Scientia Forestalis (IPEF), v. 38, p. 431-439, 2010.

PEREIRA, B. L. C.; CARNEIRO, A. C. O.; CARVAlHO, A. M. M. L.; COLODETTE, J. L.; OLIVEIRA, A. C.; FONTES, M. P. F. Influence of chemical composition of eucalyptus wood on gravimetric yield and charcoal properties. Bioresources, Raleigh, v. 8, p. 4574-4592, 2013.

PEREIRA, B. L. C.; OliveirA, A. C.; CARVAlhO, A. M. M. L.; CARNEIRO, A. C. O.; SANTOS, L. C.; VITAL, B. R. Quality of Wood and Charcoal from Eucalyptus Clones for Ironmaster Use. International Journal of Forestry Research, v. 2012, p. 1-8, 2012.

VITAL, B. R. Métodos de determinação de densidade da madeira. Viçosa: SIF, 1984. 21 p. (Boletim técnico, 1).

YANG, H.; YANB, R.; CHENA, H.; LEEB, D. H.; ZHENGA, C. Characteristics of hemicellulose, cellulose and lignin pyrolysis. Fuel, v. 86, p. 1781-1788, 2007. 